Jap. J. M. Sc. \& Biol., 15, 41-51, 1962

\title{
STUDY FOR THE STANDARDIZATION OF QUANTITATIVE TEST OF THE SUSCEPTIBILITY OF ONCOMELANIA SNAILS TO SODIUM PENTACHLOROPHENATE*
}

\author{
YOSHITAKA KOMIYA, YUKIO HOSAKA \\ AND KAZUO YASURAOKA \\ Department of Parasitology, National Institute of Health, Tokyo
}

(Received: December 25th, 1961)

As the technic for testing the susceptibility of Oncomelania snails to molluscicides two different methods are available; one is the plate method devised by McMullen (1949) and the other routine immersion one. The former was particulary devised for the screening purpose of molluscicides but is now utilized for the quantitative test of the susceptibility of snails. Considering theoretically, however, the latter would be better for the purpose, because the former, though simple in the procedure, implicates some shortness, which lies in the fact that here the snails get contact with chemicals only with a part of her body, that some snails move off the moist filter paper and that at times some of them ingest a considerable amount of filter paper. All such appear to interfere with the reproducibility of the effects. From such a viewpoint as mentioned above, a comparative examination on both methods was carried out.

For the establishment of the standardized technic, moreover, experimental study should be conducted to standardize the following subjects: a) the suitable length of time during which snails are in contact with chemicals, b) the suitable temperature at which snails are in the solution, c) the amount of the solution per snail during the test, d) the time of examining snails for their death. And finally the reproducibility of the standardized technic should be examined.

\section{MATERIALS AND METHODS}

Snails used in the following experiments were collected from the endemic area in Yamanashi Prefecture. Only snails which had emerged from their shells in a dish of dechlorinated tapwater were used.

Stock solutions were prepared by dissolving $0.1 \mathrm{~g}$ of $\mathrm{NaPCP}$ in $100 \mathrm{cc}$ of distilled water, and then a series of several twofold dilutions was made. After putting snails into the dilutions they were rinsed with running water for several minutes and placed in a Petri dish for certain length of time and then examined for their survival. The snails were judged as dead when they showed no movement after their transfer into water. Those which showed no movement were crushed to confirm their death. The $50 \%$ endpoint $\left(\mathrm{LD}_{50}\right)$ for all tests was calculated by either Behrens or Fishers method.

The other procedures will be described in each paragraph.

* This work was supported in part by research grant from World Health Organization. 小宮義孝・保阪幸男・安羅岡一男（国立予防衛生研究所寄生虫部） 


\section{RESULTS}

\section{Comparative Examination on Four Methods}

Procedure: Four technics were tested simultaneously. They were as follows:

a) Original plate method: McMullen's plate method was here slightly modified, i. e. the plate of $12 \mathrm{~cm}$ in diameter was used, and the amount of the solution applied was $5 \mathrm{cc}$.

b) Modified plate method: Here the surface of the filter paper in the plate was covered by a vinyl net of fine mess with a wooden frame to prevent snails from leaving the moist paper (vide diagram).

\section{MODIFIED PLATE METHOD}
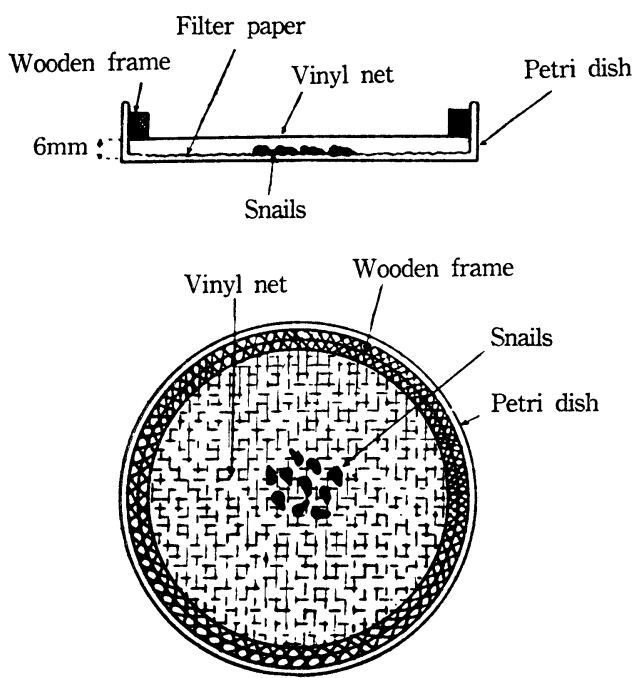

MODIFIED IMMERSION METHOD
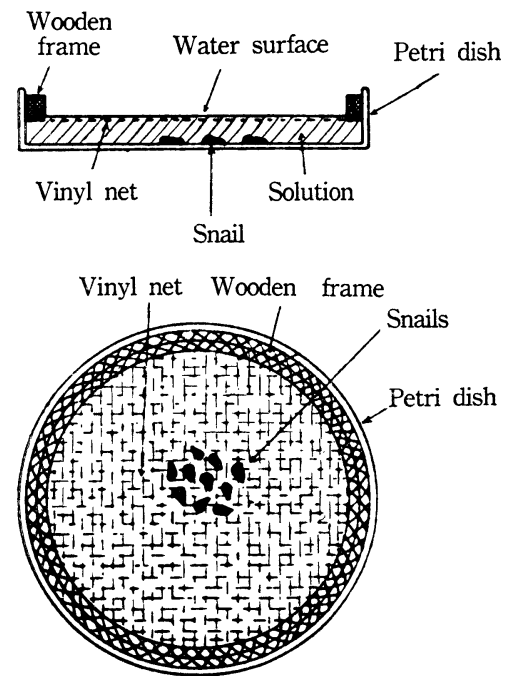

Diagram showing modified plate method and modified immersion method.

c) Routine immersion method: A Petri dish of $12 \mathrm{~cm}$ in diameter was filled with $100 \mathrm{cc}$ of solution and snails put into the solution. No preventive measure was taken to prevent snails off the solution. At intervals of a given time, however, snails which had moved off the solution were collected and were put back into the solution.

d) Modified immersion method: The main procedure was the same as in the routine one, except that the solution surface in the plate was covered with a vinyl net of fine mess with a wooden frame as in the case of the modified plate one (vide diagram).

After 48 hours in the chemical, they were rinsed with water and placed in Petri dishes for 72 hours to examine their mortality. Experiments were carried out under the room temperature $\left(10-22^{\circ} \mathrm{C}\right)$.

Results: Figs. 1 and 2 show the results. The $\mathrm{LD}_{50}$ of snails with various methods were as follows.

Original plate method $\cdots \cdots \cdots \cdot 11.3 \mathrm{ppm}(10.1-12.5 \mathrm{ppm})$

Modified plate method $\cdots \cdots \cdots \cdot 14.2 \mathrm{ppm}(13.0-15.4 \mathrm{ppm})$

Routine immersion method $\cdots \cdots 0.67 \mathrm{ppm}(0.56-0.78 \mathrm{ppm})$ 


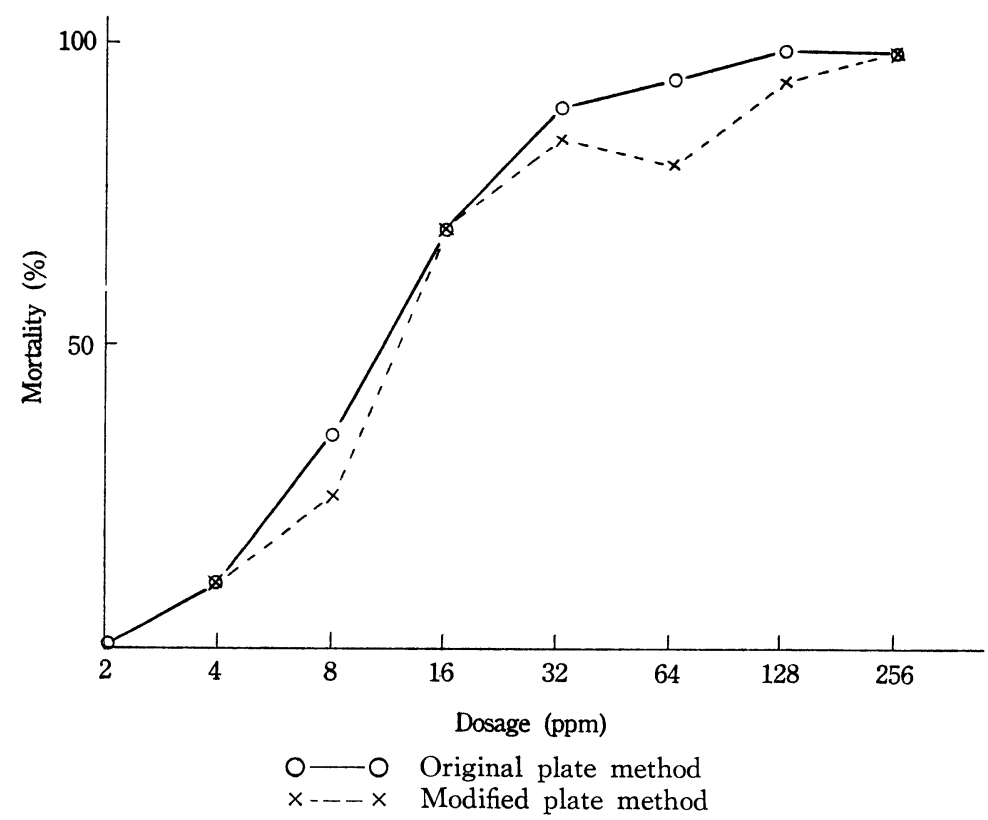

Fig. 1. Effect of NaPCP on Oncomelania nosophora by original plate methud \& modified plate method.

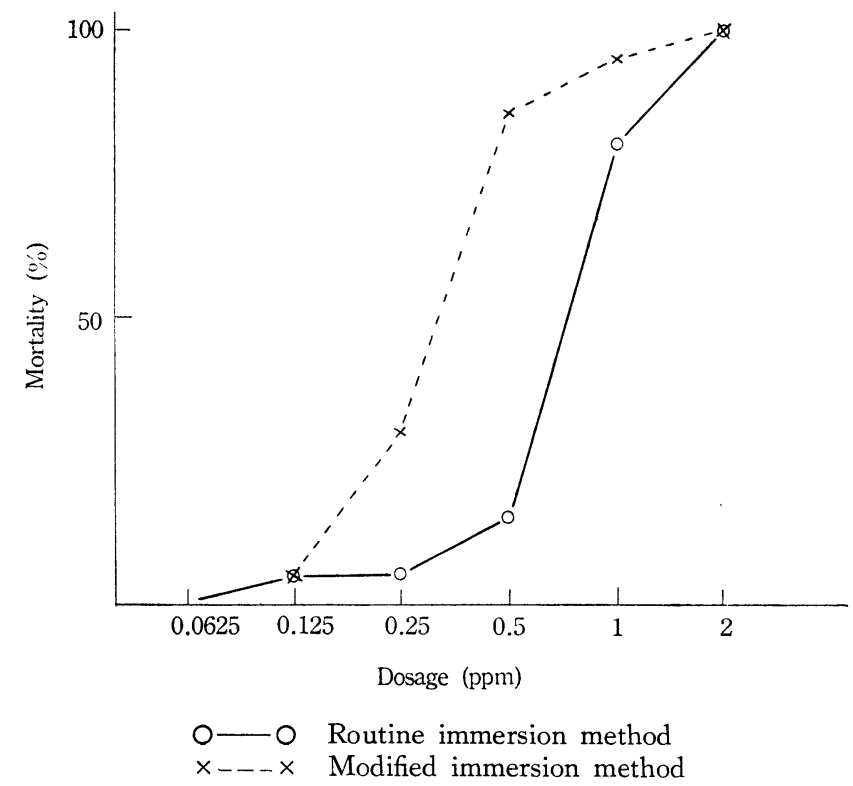

Fig. 2. Effect of NaPCP on Oncomelania nosophora by routine immersion method \& modified immersion method. 


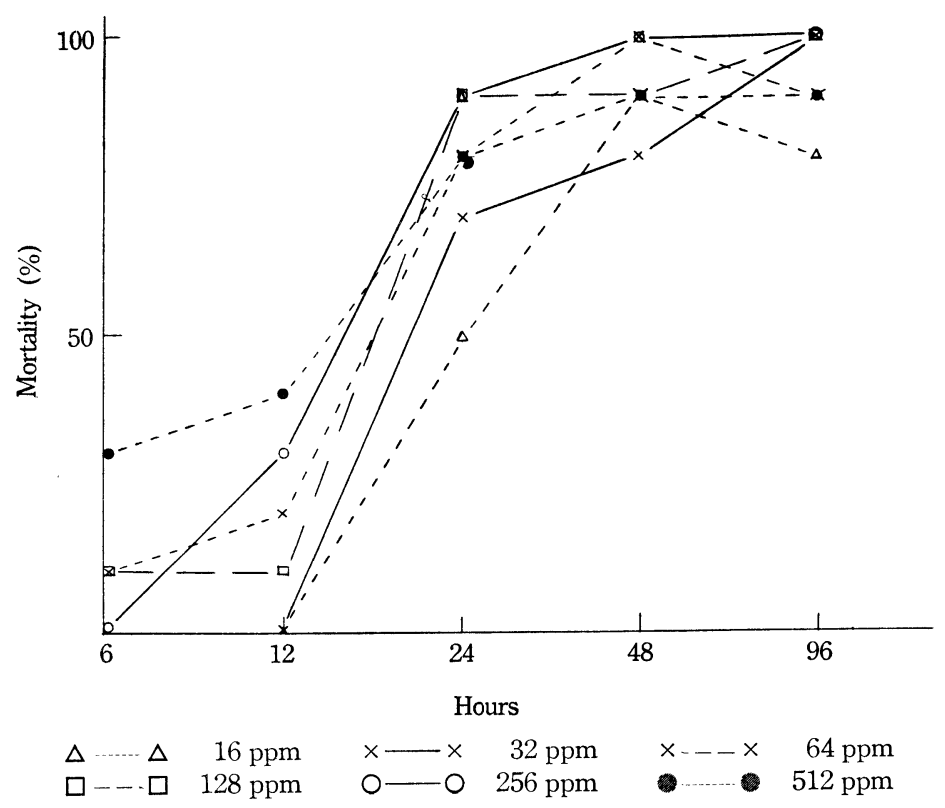

Fig. 3. Mortality of snails at various length of time exposure to NaPCP with original plate method.

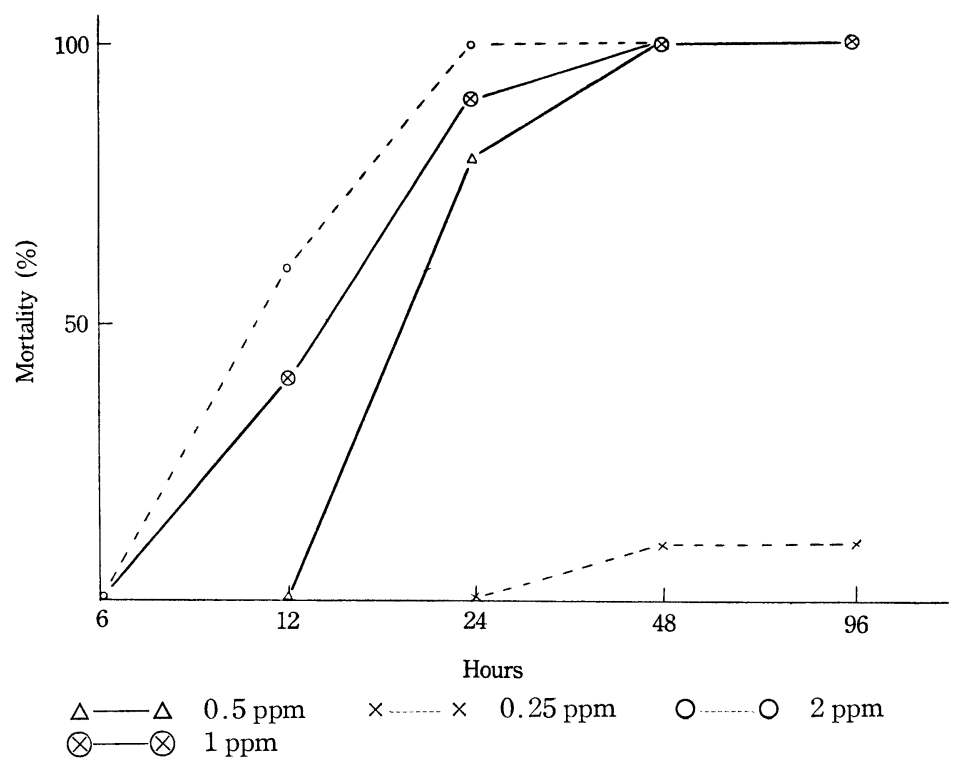

Fig. 4. Mortality of snails at various length of time exposure to NaPCP with modified immersion method. 
Modified immersion method $\cdots \cdot 0.32 \mathrm{ppm}(0.21-0.43 \mathrm{ppm})$

The molluscicidal effect of NaPCP by the modified immersion method was the most sensitive among the four.

\section{The Suitable Length of Time during Which Snails Are in Contact with Chemicals}

Procedure: Here the original plate method as well as the modified immersion one were tested. After placing snails into the chemicals their mortality was examined at intervals of $6,12,24,48$ and 96 hours respectively. The other procedures were the same as those in the previous paragraph.

Results: Figs. 3 and 4 show the results. As seen in these figures in both cases the mortality of snails attained to the maximum after 48 hours.

\section{The Suitable Temperature at Which Snails Are in the Solution}

\section{Experiment 1.}

Procedure: Here only the modified immersion method was used. Snails were divided into two groups. Those from one group were exposed to chemicals under the constant temperature of $25^{\circ} \mathrm{C}$ in an incubator, and those from the other one under the room temperature which varied between 11 and $27.5^{\circ} \mathrm{C}\left(20.5^{\circ} \mathrm{C}\right.$ on average). After 48 hours the mortality of snails under both conditions was examined comparatively.

Results: The results are shown in Table 1. As seen in this table, no marked difference was observed between the two. In $0.25 \mathrm{ppm}$ which was considered to be

Table 1. The effect of NaPCP on snails under the constant temperature and the room temperature

\begin{tabular}{|c|c|c|c|c|c|c|c|c|c|c|c|c|c|c|c|c|c|}
\hline \multirow{3}{*}{$\begin{array}{l}\text { Concen- } \\
\text { tration } \\
\text { of } \\
\mathrm{NaPCP} \\
(\mathrm{ppm}) \\
\end{array}$} & \multicolumn{9}{|c|}{ Room temperature $\left(11^{\circ}-27.5^{\circ} \mathrm{C}\right)$} & \multicolumn{8}{|c|}{ Constant temperature $\left(20.5^{\circ}-21^{\circ} \mathrm{C}\right)$} \\
\hline & \multicolumn{3}{|c|}{ No. 1.} & \multicolumn{3}{|c|}{ No. 2.} & \multicolumn{3}{|c|}{ No. 3.} & \multicolumn{2}{|r|}{ No. 1.} & \multicolumn{3}{|c|}{ No. 2.} & \multicolumn{3}{|c|}{ No. 3.} \\
\hline & \multicolumn{3}{|c|}{$\begin{array}{l}\text { No. of } \\
\text { dead / No. of } \\
\text { exposed }\end{array}$} & \multicolumn{3}{|c|}{$\begin{aligned} & \begin{array}{l}\text { No. of } \\
\text { dead / No. of } \\
\text { exposed }\end{array} \\
&\end{aligned}$} & \multicolumn{3}{|c|}{$\begin{array}{l}\text { No. of } \\
\text { dead / No. of } \\
\text { exposed }\end{array}$} & \multicolumn{2}{|c|}{$\begin{array}{l}\begin{array}{l}\text { No. of } \\
\text { dead / No. of } \\
\text { exposed }\end{array} \\
\end{array}$} & \multicolumn{3}{|c|}{$\begin{array}{l}\begin{array}{l}\text { No. of } \\
\text { dead / No. of } \\
\text { exposed }\end{array} \\
\end{array}$} & \multicolumn{3}{|c|}{$\begin{array}{l}\text { No. of } \\
\text { dead / No. of } \\
\text { exposed }\end{array}$} \\
\hline \multicolumn{18}{|l|}{ (contr.) } \\
\hline 0 & 0 & / & 10 & 0 & / & 10 & 0 & / & 10 & 0 & 10 & 0 & / & 10 & 0 & / & 10 \\
\hline 0.125 & 0 & / & 10 & 0 & / & 10 & 0 & / & 10 & 0 & 10 & 0 & / & 10 & 0 & I & 10 \\
\hline 0.25 & 2 & / & 10 & 3 & / & 10 & 6 & / & 10 & 5 & 10 & 7 & / & 10 & 7 & / & 10 \\
\hline 0.5 & 7 & l & 10 & 10 & / & 10 & 10 & / & 10 & 9 & 10 & 10 & / & 10 & 10 & / & 10 \\
\hline 1 & 10 & / & 10 & 10 & / & 10 & 10 & / & 10 & 10 & 10 & 10 & / & 10 & 10 & / & 10 \\
\hline 2 & 10 & / & 10 & 10 & / & 10 & 10 & / & 10 & 10 & 10 & 10 & / & 10 & 10 & / & 10 \\
\hline
\end{tabular}

the nearest to the $\mathrm{LD}_{50}$, however, the molluscicidal effect under the constant temperature appeared more stable than that under the room temperature.

\section{Experiment 2.}

Procedure: The molluscicidal effect, in the next place, was examined at each constant temperature of $20,25,30$ and $35^{\circ} \mathrm{C}$. The other procedures were the same as those in Experiment 1.

Results: The results are given in Table 2. As an index of the stability of method, the unbiased estimator of population variance (or mean square, M. S.) was calculated from each datum at each temperature. The dose closest to the $\mathrm{LD}_{50}$ and the $\mathrm{M}$. $\mathrm{S}$. were as follows. 
Table 2. The effect of NaPCP on snails under various temperatures

\begin{tabular}{|c|c|c|c|c|c|c|c|}
\hline \multicolumn{2}{|c|}{ Experiment number } & \multirow{2}{*}{ 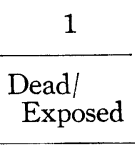 } & \multirow{2}{*}{$\frac{2}{\underset{\text { Dead } /}{\text { Exposed }}}$} & \multirow{2}{*}{ 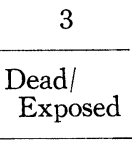 } & \multirow{2}{*}{ 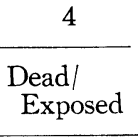 } & \multirow{2}{*}{ 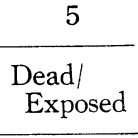 } & \multirow{2}{*}{ 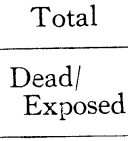 } \\
\hline Temp. & $\begin{array}{l}\text { Concent. } \\
\text { of } \mathrm{NaPCP} \\
(\mathrm{ppm})\end{array}$ & & & & & & \\
\hline \multirow{6}{*}{$\begin{array}{l}20^{\circ} \\
\pm 1^{\circ} \mathrm{C}\end{array}$} & 0 & $0 / 10$ & $0 / 10$ & & & & $0 / 20$ \\
\hline & 0.0625 & $0 / 10$ & $0 / 10$ & $0 / 10$ & $0 / 10$ & & $0 / 40$ \\
\hline & 0.125 & $0 / 10$ & $0 / 10$ & $0 / 10$ & $0 / 10$ & $0 / 10$ & $0 / 50$ \\
\hline & 0.25 & $9 / 10$ & $5 / 10$ & $6 / 10$ & $4 / 10$ & $1 / 10$ & $25 / 50$ \\
\hline & 0.5 & $10 / 10$ & 9,10 & $10 / 10$ & $10 / 10$ & $9 / 10$ & $48 / 50$ \\
\hline & 1 & $10 / 10$ & $10 / 10$ & $10 / 10$ & & & $30 / 30$ \\
\hline \multirow{6}{*}{$\begin{array}{l}25^{\circ} \\
\pm 1^{\circ} \mathrm{C}\end{array}$} & 0 & $0 / 10$ & $0 / 10$ & & & & $0 / 20$ \\
\hline & 0.0625 & $0 / 10$ & $0 / 10$ & $0 / 10$ & $0 / 10$ & $0 / 10$ & $0 / 50$ \\
\hline & 0.125 & $0 / 10$ & $1 / 10$ & $0 / 10$ & $0 / 10$ & $0 / 10$ & $1 / 50$ \\
\hline & 0.25 & $10 / 10$ & $10 / 10$ & $8 / 10$ & $4 / 10$ & $7 / 10$ & $39 / 50$ \\
\hline & 0.5 & $10 / 10$ & $10 / 10$ & $10 / 10$ & $10 / 10$ & & $40 / 40$ \\
\hline & 1 & $10 / 10$ & $10 / 10$ & & & & $20 / 20$ \\
\hline \multirow{6}{*}{$\begin{array}{l}30^{\circ} \\
\pm 1^{\circ} \mathrm{C}\end{array}$} & 0 & $0 / 10$ & $0 / 10$ & & & & $0 / 20$ \\
\hline & 0.03125 & $0 / 10$ & 0.10 & $0 / 10$ & $0 / 10$ & & $0 / 40$ \\
\hline & 0.0625 & $0 / 10$ & $0 / 10$ & $0 / 10$ & $0 / 10$ & $0 / 10$ & $0 / 50$ \\
\hline & 0.125 & $1 / 10$ & $0 / 10$ & $8 / 10$ & $1 / 10$ & $0 / 10$ & $10 / 50$ \\
\hline & 0.25 & $10 / 10$ & $10 / 10$ & $10 / 10$ & $9 / 10$ & $10 / 10$ & $49 / 50$ \\
\hline & 0.5 & $10 / 10$ & $10 / 10$ & $10 / 10$ & & & $30 / 30$ \\
\hline \multirow{6}{*}{$\begin{array}{l}35^{\circ} \\
\pm 1^{\circ} \mathrm{C}\end{array}$} & 0 & $2 / 10$ & $0 / 10$ & & & & $2 / 20$ \\
\hline & 0.03125 & $3 / 10$ & $5 / 10$ & $1 / 10$ & $9 / 10$ & $7 / 10$ & $25 / 50$ \\
\hline & 0.0625 & $7 / 10$ & $9 / 10$ & $10 / 10$ & $8 / 10$ & $8 / 10$ & $42 / 50$ \\
\hline & 0.125 & $10 / 10$ & $10 / 10$ & $10 / 10$ & $10 / 10$ & $10 / 10$ & $50 / 50$ \\
\hline & 0.25 & $10 / 10$ & $10 / 10$ & & & & $20 / 20$ \\
\hline & 0.5 & $10 / 10$ & $10 / 10$ & & & & $20 / 20$ \\
\hline
\end{tabular}

$\begin{array}{ccr}\text { Temperature } & \text { Dose nearest } \mathrm{LD}_{50} & \text { M. S. } \\ 20^{\circ} \mathrm{C} & 0.25 \mathrm{ppm} & 8.5 \\ 25^{\circ} \mathrm{C} & 0.25 \mathrm{ppm} & 6.3 \\ 30^{\circ} \mathrm{C} & 0.125 \mathrm{ppm} & 9.5 \\ 35^{\circ} \mathrm{C} & 0.03125 \mathrm{ppm} & 10.0\end{array}$

Thus, the molluscicidal effect seems to be more stable at $25^{\circ} \mathrm{C}$ because the M. S. was the lowest at this temperature.

\section{The Amount of the Solution per Snail during the Test}

Procedure: Moon et al. (1958) devised an immersion method in order to cover up an imperfection in the plate method. According to their method 10 snails are submerged into $20 \mathrm{cc}$ vials which were filled to the brim with the solution and covered with glass slides. In our immersion method, up to now, 10 snails are submerged into Petri dishes of $12 \mathrm{~cm}$ in diameter containing $100 \mathrm{cc}$ solution. There is a marked difference in the amount of solution per snail between the two methods. In the fol- 
lowing experiment, therefore, to know the suitable amount of the solution per snail during the test our modified immersion method was compared with Moon's one. The temperature during the experiment varied between 20 and $22^{\circ} \mathrm{C}$.

Results: As seen in Table 3, in Moon's method a high mortality of snails was observed even in water control, and such a tendency was also found in such lower concentrations as $0.03125 \mathrm{ppm}$ and $0.0625 \mathrm{ppm}$. In our method, on the contrary, dead snails were found in the solution of $0.25 \mathrm{ppm}$ and over.

Table 3. Effect of NaPCP on Oncomelania nosophora by modified immersion method \& Moon's immersion method

\begin{tabular}{lccccc}
\hline $\begin{array}{c}\text { Concentration } \\
\text { of } \begin{array}{c}\text { NaPCP } \\
(\mathrm{ppm})\end{array}\end{array}$ & \multicolumn{2}{c}{ Modified immersion method } & & \multicolumn{2}{c}{ Moon's immersion method } \\
\cline { 2 - 3 } \cline { 5 - 6 } & No. of alive & No. of dead & & No. of alive & No. of dead \\
\hline 0 (contr.) & 10 & 0 & & 4 & 6 \\
0.03125 & 10 & 0 & & 3 & 7 \\
0.0625 & 10 & 0 & & 7 & 3 \\
0.125 & 10 & 0 & & 4 & 6 \\
0.25 & 0 & 10 & & 0 & 10 \\
0.5 & 0 & 10 & & 0 & 10 \\
1 & 0 & 10 & & 0 & 10 \\
2 & 0 & 10 & & 0 & 10 \\
4 & 0 & 10 & & 0 & 10 \\
8 & 0 & 10 & & 0 & 10 \\
\hline
\end{tabular}

\section{The Time of Examining Snails for Their Death}

Procedure: In this experiment, only the modified immersion method was used. Snails were divided into 4 equal groups of 70 snails each and exposed to $0.1875 \mathrm{ppm}$ solution of the compound which was considered to be the most approximate to the $\mathrm{LD}_{50}$. All were kept immersed for 48 hours in an incubator at $25^{\circ} \mathrm{C}$. At the conclusion of the exposure, all snails were rinsed with running water and placed into Petri dishes, $10 \mathrm{~cm}$ in diameter and $1.2 \mathrm{~cm}$ in height, containing $c a .100 \mathrm{cc}$ of dechlorinated tap water for 24 hours in the first group, 48 hours in the second, 72 hours in the third and 96 hours in the fourth. At the end of these periods the survival of snails was determined initially on the basis of movement and then snails whose survival was obscure were crushed lightly to confirm it. On the other hand, in cases of the second, third and fourth groups the examination of survival was made at a 24 hour interval without crushing them. During these periods, the water in Petri dishes was renewed completely every 24 hours.

Results: The data are presented in Fig. 5 in bar diagram form. It seems likely, on the basis of the present data, that the survival or death of snails becomes stable 48 hours after placing them into water.

\section{The Reproducibility of Molluscicidal Effect with Various Methods}

Procedure: Here the comparative examination on the reproducibility of mollusci- 


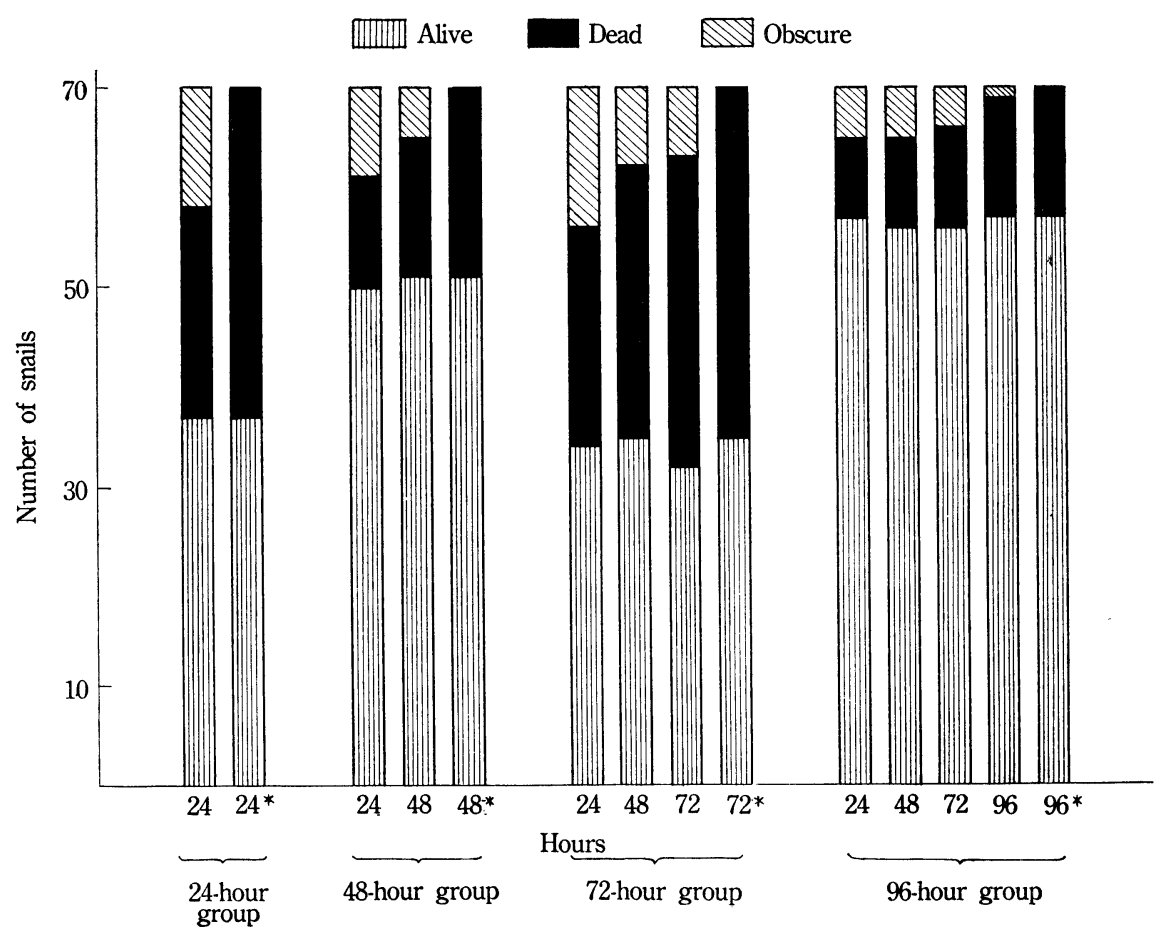

Fig. 5. The hourly change of the number of alive and dead snails after the exposure.

* At this time, snails were crushed to confirm their death.

cidal effect was performed on four different methods, namely the original plate method, the modified plate method, the routine immersion method and the modified immersion method. First of all, the $\mathrm{LD}_{50}$ was measured with each of four methods, and then at each $\mathrm{LD}_{50}$ the mortality of snails was examined.

Results : Table 4 shows the results. The mortality of snails at each $\mathrm{LD}_{50}$ was as follows : $62 \%$ in the original plate method, $31 \%$ in the modified plate method, $40 \%$ in the routine immersion method and $45 \%$ in the modified immersion method. Thus the mortality with the modified immersion method was found to be the nearest to the $50 \%$ mortality. On the other hand, similarly as in paragraph 3 , the unbiased estimator of population variance (M. S.) which was calculated in each method were as follows: 2.4 in the original plate method, 1.4 in the modified plate method, 2.0 in the routine immersion method and 1.2 in the modified immersion method. Thus the M. S. in the modified immersion method was also found to be the lowest among those four methods. These results may be taken to indicate that the highest reproducibility and stability of the effect was found in the modified immersion method.

\section{DISCUSSION AND CONCLUSION}

For the establishment of the standardized method for testing the susceptibility of Oncomelania snails to chemicals, the technic for contacting snails to chemicals should be selected at first. It should be accurate, reproducible and convenient. As has been 
Table 4. Mortality of snails in the $\mathrm{LD}_{50}$ of $\mathrm{NaPCP}$ as determined previously with four methods

\begin{tabular}{|c|c|c|c|c|c|c|c|c|}
\hline \multirow{2}{*}{$\begin{array}{l}\text { No. of } \\
\text { examined }\end{array}$} & \multicolumn{2}{|c|}{$\begin{array}{l}\text { Original plate } \\
\text { method }\end{array}$} & \multicolumn{2}{|c|}{$\begin{array}{l}\text { Modified plate } \\
\text { method }\end{array}$} & \multicolumn{2}{|c|}{$\begin{array}{l}\text { Routine immersion } \\
\text { method }\end{array}$} & \multicolumn{2}{|c|}{$\begin{array}{c}\text { Modified immersion } \\
\text { method }\end{array}$} \\
\hline & $\begin{array}{l}\text { No. of } \\
\text { exposed }\end{array}$ & $\begin{array}{l}\text { No. of } \\
\text { dead }\end{array}$ & $\begin{array}{l}\text { No. of } \\
\text { exposed }\end{array}$ & $\begin{array}{l}\text { No. of } \\
\text { dead }\end{array}$ & $\begin{array}{c}\text { No. of } \\
\text { exposed }\end{array}$ & $\begin{array}{l}\text { No. of } \\
\text { dead }\end{array}$ & $\begin{array}{l}\text { No. of } \\
\text { exposed }\end{array}$ & $\begin{array}{c}\text { No. of } \\
\text { dead }\end{array}$ \\
\hline 1 & 10 & 4 & 10 & 3 & 10 & 6 & 10 & 6 \\
\hline 2 & 10 & 5 & 10 & 4 & 10 & 2 & 10 & 4 \\
\hline 3 & 10 & 6 & 10 & 4 & 10 & 4 & 10 & 5 \\
\hline 4 & 10 & 5 & 10 & 3 & 10 & 3 & 10 & 3 \\
\hline 5 & 10 & 9 & 10 & 1 & 10 & 2 & 10 & 3 \\
\hline 6 & 10 & 8 & 10 & 3 & 10 & 4 & 10 & 5 \\
\hline 7 & 10 & 7 & 10 & 5 & 10 & 6 & 10 & 6 \\
\hline 8 & 10 & 5 & 10 & 4 & 10 & 4 & 10 & 4 \\
\hline 9 & 10 & 7 & 10 & 2 & 10 & 4 & 10 & 4 \\
\hline 10 & 10 & 6 & 10 & 2 & 10 & 5 & 10 & 5 \\
\hline Control & 10 & 0 & 10 & 0 & 10 & 0 & 10 & 0 \\
\hline
\end{tabular}

disclosed in paragraphs 1 and 5, among the four methods the modified immersion one appeared more suitable for the purpose.

As to the length of time during which snails are in the solution, in the original plate method and Moon's immersion one, it was determined as 96 and 6 hours, respectively. According to the results of our experiments, however, 48 hours would suffice for the purpose.

As regards the temperature at which snails are in the solution, an experiment of this kind has been performed under the room temperature up to now. According to the results obtained in paragraph 3 , the test under the constant temperature of $25^{\circ} \mathrm{C}$ was found to give more stability to the effect. But it should be a question that snails were placed under such a darkness as in the incubator. As to this point, it may be left out of consideration because Yasuraoka (1962) stated that the behavior of snails in darkness in almost the same as that in light.

As to the amount of the solution per snail during the test, in Moon's immersion method and ours 20 and $100 \mathrm{cc}$ per 10 snails are used, respectively. As has been carried out in paragraph 4, in Moon's method the fact that high mortality was found even in water control may be attributed to the lack of oxygen in the solution. In fact, Yanagisawa et at. (1961) stated that oxygen consumption per adult snail was about $4.5 \mu 1 / \mathrm{hr}$ at $30^{\circ} \mathrm{C}$. The amount of oxygen in water, in general, is $5.26 \mathrm{cc} / 1$ at $30^{\circ} \mathrm{C}$, so that in Moon's method oxygen in $20 \mathrm{cc}$ vial is only about $105 \mu 1$. Oxygen in water is so small an amount that 10 snails will consume it up within 2 or 3 hours. To use the solution of $100 \mathrm{cc}$ per 10 snails would suffice for the amount of the solution.

As for the time of examining snails for their death, in Moon's immersion method snails were placed in water for 66 hours and in McMullen's plate method for several hours, and at these times the shells were crushed and the number of living snails recorded. From the data given in Fig. 5, however, it will be seen that the survival or death of snails is to be examined 48 hours after placing them in water.

From the results as mentioned above, the method for testing the susceptibility of 
Oncomelania snails to water-soluble chemicals was considered to be performed by the following procedures.

1) Snails used: The snails are to be collected from the same area at the same time, their shell length being $6.5 \mathrm{~mm}$ and over.

2) The container: The container for testing is to be a Petri dish with a cover measuring $c a .12 \mathrm{~cm}$ in diameter and $2.5 \mathrm{~cm}$ in height.

3) The compound to be tested: The compound to be tested is to be diluted by two-fold steps with distilled water, e.g. 1/5,000,1/10,000,1/20,000,1/40,000 and $1 / 80,000$ and so on.

4) About $100 \mathrm{cc}$ of the solution of the compound of the respective dilution is to be put in the respective Petri dish in which every 10 snail specimens are to be put. A vinyl net of fine mess with a wooden frame is to be put in the inside of the dish on the water surface to prevent the snails from leaving the solution (vide diagram).

5) Every dish with a cover is to be put in an incubator of $25^{\circ} \mathrm{C}$ for 48 hours.

6) After 48 hours every dish is to be put out of the incubator, and the snails are to be rinsed in running water for several minutes.

7) The snails washed are to be put into the other Petri dish filled with dechlorinated tap water ( $\mathrm{ca} .100 \mathrm{cc}$ in each dish) and are to be put in the incubator above mentioned for 48 hours, after which their life or death is to be examined.

8) From the results of the above procedure the $\mathrm{LD}_{50}$ is to be calculated.

\section{SUMMARY}

For the establishment of the standardized technic for testing the susceptibility of Oncomelania snails to sodium pentachlorophenate, four methods (original plate method, modified plate method, routine immersion method and modified immersion method) were examined experimentally in the laboratory. As a result of this the conclusion was induced that the modified immersion method was recommendable. On the other hand, (1) the length of time during which snails are in contact with chemicals, (2) the temperature at which snails are in the solution, (3) the amount of the solution per snail during the test, and (4) the time of examining snails for their death were also standardized.

\section{REFERENCES}

Hoffman, D. O. \& ZAKHAEY, R. (1951): The effect of temperature on the molluscicidal activity of cupper sulphate. Science, 114, 521-523.

HosAKA, Y. (1959): Study on the standardized technics for testing the susceptibility of Oncomelania snail to molluscicides. Jap. J. Parasit., 8, 102-107 (text in Japanese with English summary).

Hunter, G. W. III, Freytag, R. E. \& Ritchie, L. S. (1952) : Potential molluscicides screened in the laboratory and the results of preliminary field plot test. J. Parasit., 38, 509-516.

KunTZ, R. E. (1957) : Relationship of temperature to molluscicidal activity. Am. J. Trop. Med. \& Hyg., 6, 940-945.

McMullen, D. B., Ishi, N. \& Mitoma, Y. (1948): Results of screening tests on chemicals as molluscicides. J. Parasit., 34, 33 (Suppl.).

McMullen, D. B. (1949): A plate method of screening chemicals as molluscicides. J. Parasit., 35, 28 (Suppl.).

McMullen, D. B. (1952): Schistosomiasis and molluscicides. Am. J. Trop. Med. \& Hyg., 1, 
$671-679$.

MoOn, A. P., Frick, L. P. \& AsakaWA, S. (1958): Laboratory screening of compounds for molluscicidal activity against Oncomelania nosophora with an immersion test and a modified plate test. Am. J. Trop. Med. \& Hyg., 7, 295-297.

Nolan, M. C., Bond, H. W. \& MANN, E. R. (1953): Results of laboratory screening test of chemical compounds for molluscicidal activity. I. Phenol and related compounds. Am. J. Trop. Med. \& Hyg., 2, 716-752.

OKABE, K. \& SHIBUE, H. (1952) : Molluscicidal effect of PCP-Na on Oncomelania nosophara. Kurume M. J., 15, 436-440 (text in Japanese with English summary).

YANAGiSAWA, T. \& KOMIYA, Y. (1961): Physiological studies on Oncomelania nosophora, the vector snali of Schistosoma japonicum. I. On the oxygen uptake and effect of starvation upon it. Jap. J. M. Sc. \& Biol., 14, 69-76.

YASURAOKA, K. (1962): Behavior of Oncomelania nosophora under the total darkness (in press). 